\title{
FEMINISME LIBERAL DALAM NOVEL ENTROK KARYA OKKY MADASARI
}

\author{
Defani Amanda Putri \\ (Program Studi Pendidikan Bahasa Indonesia, Fakultas Keguruan dan Ilmu Pendidikan, \\ Universitas PGRI Adi Buana Surabaya) \\ dinardinar904@gmail.com
}

\section{Sri Budi Astuti}

(Program Studi Pendidikan Bahasa Indonesia, Fakultas Keguruan dan Ilmu Pendidikan, Universitas PGRI Adi Buana Surabaya) sri.budi@unipasby.ac.id

\begin{abstract}
Feminism or the one known as empasipasi comes from Latin which means woman. Feminism is an awareness of deterrence and the fulfillment of the eremgum dálan maspmiat, the place of work and in the family, and the conscious actions of women and men to change the situation in Okky Madasari's Entrok novel. The purpose of this study is to describe more deeply, adequately and comprehensively about liberal feminism in the novel Entrok by Okky Madasari. The theory used in this study is liberal feminism according to Sugihastuti. The method used in this study is descriptive qualitative research method. The data collection technique of this study uses documentation techniques. The data analysis technique of this research uses descriptive qualitative. The results of the research found in liberal feminism by Okky Madasari's Entrok novel are that literary texts do not have a single meaning, literary texts always produce new interpretations that are not previously thought. In the Entrok novel researchers found that equal rights or inequality among women. Men are powerful and think that women are below them.
\end{abstract}

Keywords: liberal feminism, a form of gender injustice, male inequality

\section{PENDAHULUAN}

Sastra adalah ungkapan pribadi manusia yang berupa pengalaman, pemikiran, perasaan, ide, semangat, keyakinan dalam suatu bentuk gambaran konkret yang membangkitkan pesona dengan alat bahasa. Sehingga sastra memiliki unsur-unsur berupa pikiran,pengalaman, ide, perasaan, semangat, kepercayaan (keyakinan), ekspresi atau ungkapan, bentuk dan bahasa. Hal ini dikuatkan oleh pendapat Saryono (2009: 18) bahwa sastra juga mempunyai kemampuan untuk merekam semua pengalaman yang empiris-natural maupun pengalaman yang nonempirissupernatural, dengan kata lain sastra mampu menjadi saksi dan pengomentar kehidupan manusia. Sumardjo \& Saini (1997:3-4)

Karya sastra dapat dibagi menjadi tiga, yaitu: prosa (fiksi), puisi, dan drama. Prosa dalam pengertian kesastraan juga disebut fiksi (fiction), teks naratif (narrative discource). Istilah fiksi dalam pengertian ini berarti cerita rekaan atau cerita khayalan (Nurgiantoro, 2013:2). Salah satu contoh prosa fiksi tersebut adalah novel.

Novel merupakan sebuah totalitas, yaitu suatu kemenyeluruhan 
yang bersifat artistik. Sebagai sebuah totalitas, novel mempunyai bagianbagian, unsur-unsur yang saling berkaitan satu dengan yang lain secara erat dan saling menggantungkan. Dalam hal ini, novel dibangun atas unsur ekstrinsik dan intrinsik. Seperti yang diungkapkan oleh Nurgiyantoro (2005: 4), di dalam novel terdapat tema, amanat, karakteristik tokoh, alur, latar cerita, dan sudut pandang cerita (point of view). Selain itu, setiap novel senantiasa menawarkan pesan moral atau amanat yang berhubungan dengan sifat-sifat kemanusiaan. Hal tersebut tersampaikan melalui cerita, sikap, dan tingkah laku tokoh-tokohnya.

Karya sastra yang berbentuk fiksi,seperti novel,selalu mempunyai beragam kisah, tujuan pada cerita yang terdapat di dalamnya, dan nilainilai pendidikan yang terkadung. Salah satu syarat sebuah novel yang dapat dikatakan baik adalah novel yang bisa membuat pembacanya ikut merasakan berada dalam cerita dan bisa larut dalam kisah yang diceritakan.

Feminisme liberal adalah pandangan untuk menempatkan perempuan yang memiliki kebebasan secara penuh dan individual (Sugihastuti, 2010:10). Feminisme liberal meliputi tiga unsur yaitu: a. bentuk ketidakadilan gender, $b$. ketidaksetaraan antara laki-laki dan perempuan, c. penindasan laki-laki terhadap perempuan. Sehubungan dengan pemaparan tersebut, novel Entrok karya Okky Madasari ini sangat menarik untuk dijadikan penelitian pendekatan feminisme liberal.

Kajian mengenai Feminisme telah dilakukan oleh penelitian sebelumnya Feminisme dalam Novel
Perempuan Berkalung Sorban karya Abidah El Khaliqy. Rani Nuraeni. FKIP Universitas Galuh Jawa Barat.

Penelitian terdahulu yang dilakukan oleh Rani Nuraeni yang berjudul Feminisme Dalam Novel Perempuan Berkalung Sorban Karya Abidah El Khaliqy. Penelitian yang ditulis oleh Rani Nuraeni selesai pada tahun 2017 yang ditinjau dari segi feminisme, novel, gender, marginalisasi, subordinasi, kekerasan, beban kerja. Penelitian yang diteliti oleh Rani Nuraeni terdiri atas beberapa pembahasan dari rumusan masalah yang diteliti. Pertama,peneliti ini membahas tentang Marginalisasi terhadap perempuan pada tokoh utama. Salah satu unsur feminisme dalam novel Perempuan Berkalung Sorban bentuk ketidak adilan yaitu marginalisasi. Marginalisasi pada perempuan merupakan batasan-batasan yang di terima oleh kaum perempuan. Nilainilai patriarki yang sangat kental membuat kaum perempuan mengalami diskriminasi dalam kehidupannya. Dalam novel Perempuan Berkalung Sorban disinggung bagaimana cara mendidik orang tua yang selalu membedabedakan perlakuan untuk anak lakilaki dan anak perempuan. Hal ini dialami oleh tokoh utama yang selalu mendapatkan perlakuan yang beda dengan sodara laki-lakinya.

Penelitian terdahulu dalam penelitian ini lebih difokuskan feminisme liberal dan menggunakan novel entrok karya Okky madasari. Sedangkan penelitian terdahulu Rani Nuraeni lebih menekankan pada penelitian analisis unsur feminisme sastra terhadap novel Perempuan Berkalung Sorban Karya Abidah El Khaliqy. 
Penelitian terdahulu berikutnya Feminisme dalam Novel Bibir Merah karya Achmad Munif. Indayani . Universitas PGRI Adi Buana Surabaya.

Penelitian lainnya yang dianggap relevan dengan penelitian ini adalah penelitian yang dilakukan oleh Indayani yang berjudul Feminisme Dalam Novel Bibir Merah Karya Achmad Munif penelitian yang ditulis oleh Indayani pada tahun 2014 yang ditinjau dari segi feminisme, prilaku dan sikap tokoh utama. Penelitian yang diteliti oleh Indayani terdiri atas beberapa pembahasan dari rumusan masalah yang diteliti. Pertama, peneliti ini membahas tentang Trauma yang dialami Rumanti. Masa lalu merupakan masa yang telah dijalani. Bila masa lalu itu berupa kebahagiaan, maka masa lalu itu patut untuk dikenang. Bila sebaliknya, masa lalu itu pahit maka tidak seharusnya diingat. Rumanti adalah seorang perempuan yang mempunyai masa lalu yang pahit. Ia hampir tidak biasa melupakan masa lalunya. Ia selalu dibayangi masa lalu yang suram. Kehidupan Rumanti sudah berbalik 360 derajat tetapi masih ada luka yang mendalam. Luka yang tidak dapat dihapus walaupun digantikan dengan kekayaan, jabatan, dan segala materi yang ia miliki sekarang.

Penganalisisan dari penelitian ini lebih difokuskan pada feminisme liberal dan menggunakan novel entrok karya Okky madasari. Sedangkan penelitian terdahulu Indayani lebih menekankan pada penelitian analisis unsur feminisme terhadap perilaku dan sikap tokoh utama terhadap novel Bibir Merah Karya Achmad Munif .

\section{METODE PENELITIAN}

Pada penelitian ini digunakan penelitian deskriptif kualitatif. Pendekatan deskriptif adalah pendekatan yang bertujuan untuk membuat gambaran atau lukisan secara sisitematis, faktual dan akurat mengenai fakta-fakta, sifatsifat serta hubungan antar fernomena yang diselidiki. Penelitian ini menhasilkan data deskriptif berupa kata-kate tertulis. Dalam pendekatan deskriptif, data yang dikumpulkan berupa kata-kata, gambar bukan angka-angka Moleong (2014:6). Metode adalah cara kerja yang bersistem untuk memudahkan pelaksanaan suatu kegiatan guna mencapai tujuan tertentu. Metode dianggap sebagai cara-cara, strategi untuk memahami realitas, langkahlangkah sistematis untuk memecahkan rangkaian sebab akibat berikunya, berfungsi untuk menyederhanakan masalah sehingga lebih mudah untuk dpecahkan dan dipahami (prapodo, 2001:34). Data dalam penelitian ini berupa kata atau kalimat pada kutipan yang mengandung feminisme liberal yang meliputi: ketidaksetaraan antara lakilaki dan perempuan, bentuk ketidakadilan gender, serta penindasan laki-laki terhadap perempuan. Sumber data dalam penelitian ini adalah novel yang berjudul Entrok karya Okky Madasari yang diterbitkan oleh PT Gramedia Pustaka Utama pada tahun 2010. Novel ini telah mengalami dua kali cetak pada bulan maret 2015, dengan ketebalan 288 halaman. Teknik pengumpulan data dalam penelitian ini digunakan berupa dokumentasi. Teknik dokumentasi menurut (Sugiyono,2013:82). Teknik analisis data dalam penelitian ini digunakan deskriptif kualitatif. Menurut Moleong, 2011:248) teknik analisis 
data deskriptif kualitatif adalah upaya yang dilakukan dengan jalan berkerja dengan data, memilah-milahnya menjadi satuan yang dapat dikelola, mensistensikannya, mencari dan menemukan pola, menemukan apa yang penting dan apa yang dipelajari, dan memutuskan apa yang dapat diceritakan kepada orang lain.

\section{HASIL PENELITIAN DAN PEMBAHASAN}

Hasil penelitian ini berupa feminisme liberal dalam novel Entrok karya Okky Madasari yang meliputi dalam bentuk ketidakadilan gender, ketidaksetaraan antara laki-laki dan perempuan, serta penindasan laki-laki terhadap perempuan, dapat diuraikan sebagai berikut:

1. Bentuk ketidakadilan Gender Ketidakadilan gender merupakan kondisi kesenjangan atau ketimpangan, akibat dari sistem tersebut. Ketidakadilan pada gender terjadi karena adanya keyakinan dan pembenaran yang ditanamkan sepanjang peradapan manusia ada dalam berbagai bentuk. Dalam novel Entrok karya Okky Madasari mmengambarkan tentang sosok perempuan yang berkerja keras untuk kelangsungan hidupnya dan keluarganya sendiri dengan berjualan. Novel ini juga mengambarkan ketidakadilan dan deskriminasi gender yang terjadi kerena adanya keyakinan pada masyarakat. Perempuan selalu terlihat lebih rendah dari pada laki-laki, perempuan lah yang lebih banyak myerasakan ketidakadilan gender. Adapun kutipan sebagai berikut:

"sedulur-sedulur, si Iyem ini sundal. Suami orang direbut juga" teriak Yu Parti dengan penuh amarah. Yu Yem, yang terlihat takut, terpancing dan mulai marah. Dengan suara tak kalah kencang, dia membalas kata-kata Yu Parti. "Enak saja, nyebut aku sudal. Sampeyan sendiri yang tidak bisa ngeladeni suami. Bukan salahku kalau suami sampeyan mau kawin sama aku.". "Dasar sundal, perebut suami orang." $\mathrm{Yu}$ Parti mulai kehilangan kesabaran. Dia bergerak mendekati tempat $\mathrm{Yu}$ Yem berdiri. Dagangan cabe yang ada di los disapu dengan tanganya. Cabe-cabe itu berhamburan ke seluruh los (Entrok,2010:26).

Berdasarkan kutipan di atas, dapat diartikan bahwa wanita dimata lakilaki seperti murahan, semua laki-laki memang selalu merendahkan dan menghina perempuan. Bentuk ketidakadilan gender bisa dilihat dari ungkapan "Sedulur-sedulur, si iyem ini sudal" mereka menghina iyem bukan perempuan baik-baik.

Menjadi perempuan pekerja keras tidaklah gampang akan selalu ada fikiran tidak baik masyarakat terhadap perempuan. Mereka selalu berfikir keburukan kita padahal apa yang kita jalani seutuhnya hanya untuk memnuhi kebutuhan rumah. Adapun kutipanya sebagai berikut:

"Yu marni, Kang teja, kami mendengar dari orang katanya sampeyan ngerenteni duit. Itu dilarang agama. Kalian bikin sensara banyak orang". "E... e... e... kang, aku bikin sengsara orang bagaimana? Mereka butuh uang, ya aku tolong. Kalau mereka ndak butuh, aku ya lebih seneng bakulan barang". "Pokoke, yu kami tidak mau ada rentenir 
didesa kami. Kami tidak mau ada yang buat dosa di sini". "Gusti nyuwun pangapura! Dosa apa aku, kang? Apa dosa kalau aku mencari makan, cari duit, supaya anakku bias sekolah? Yang penting aku tidak mencuri, tidak merampok, tidak menipu orang, tidak membunuh! Dosa apa aku?". "Pokoknya, yu. Apapun alasanya, tidak boleh ada rentenir di desa ini. Kalau sampeyan memaksa, kami bias lapor kepolisi”. (Entrok,2010:75)

Berdasarkan kutipan di atas, dapat diartikan bahwa laki-laki menilai perkerjaan yang dikerjakan wanita itu tidak baik. Bentuk ketidakadilan gender bisa dilihat dari kutipan "Pokoke, yu kami tidak mau ada rentenir didesa kami. Kami tidak mau ada yang buat dosa di sini" laki-laki berbicara seenaknya sendiri menghakimi wanita, padahal wanita ini berkerja untuk kehidupan keluarganya.

2. Ketidaksetaraan antara Lakilaki dan Perempuan

Ketidaksetaraan antara lakilaki dan perempuan merupakan ketidaksamaan antara laki-laki dengan perempuan untuk memperoleh kesempatan dan hakhaknya, agar mampu berperan dan berpartisipasi dalam kegiatan politik, hukum ekonomi, sosial budaya, pendidikan, pertahanan dan keamanan nasional, serta kesamaan dalam menikmati hasil pembangunan

tersebut.Ketidaksetaraan dalam ekonomi, hukum, sosial budaya, pendidikan, dan keamanan, serta kesamaan dalam menikmati hasil pembagunan tersebut. Hal tersebut dapat di lihat pada kutipan di bawah ini:

"aku tak bicara tentang entrok kepada Simbok. Aku hanya berkata ingin membantunya mengupas singkong. siapa tahu bisa dapat uang. Simbok berkata, aku tak akan mendapat uang. Kebiasaan di pasar, buruh-buruh perempuan diupahi dengan bahan makanan. Beda dengan kuli laki-laki yang diupahi dengan uang" (Entrok,2010:22).

Berdasarkan kutipan di atas letak sebuah feminisme liberal dalam bentuk ketidaksetaraan antara lakilaki dan perempuan pada kutipan "kebiasaan di pasar buruh-buruh perempuan diupahi dengan bahan makanan. Beda dengan laki-laki yang diupahi dengan uang" dari kutipan tersebut dapat disimpulkan bahwa meskipun wanita berkerja keras mereka tidak akan mendapatkan uang melaikan mereka mendapatkan bahan makanan. Sedangkan laki-laki mereka akan mendapatkan uang. Seperti tidak adil antara laki-laki dan perempuan berbeda padahal mereka sama-sama berkerja.

Tidak semua perkerjaan bisa dikerjakan perempuan namun pada novel ini untuk mendapatkan uang hanya perkerjaan laki-laki atau berdangang di pasar. Ketidaksetaraan antara laki-laki dan perempuan yang menyebabkan semua menjadi tidak adil atau ketidaksamaan antara laki-laki dan perempun. Hal tersebut dapat kita lihat pada kutipan di bawah ini:

"Nyi Dimah mau ngangkat apa?". "bukan kang. Aku ngak di suruh nyai. Aku yang butuh bantuan, kang". "kamu mau ngangkat apa, Ni?. "Bukan, 
kang. Bukan minta dibantu ngangkat. Aku mau di tolong, aku mau ikut nguli kayak kakang."teja tebahak-bahak mendengar Permintaanku. Sangguh bukan jawaban seperti itu yang kuinginkan. Aku menunggu agak lama untuk mendapatkan jawaban yang sebenarnya. "Ni, kamu ada-ada saja. Nggak ada perempuan nguli, Nggak akan kuat. Sudah, perempuan itu kerja yang ringan-ringan aja. Ngupas singkong". "Aku kuat, Kang. Biasanya aku juga nggendong tenggok, nggendong goni. Bakul-bakul itu juga banyak yang mengangkat sendiri dagangannya dari rumah ke pasar. Hanya priyayi-priyayi saja yang nggak kuat ngangkat goni." "Tapi tetap nggak umum, Ni. Di pasar ini, nggak ada perempuan nguli". "Tapi aku man, Kang. Aku butuh duit, Kang. Nggak man lagi diupahi singkong". "Ya terserah. Kalau mau nguli ya monggo," Kata Teja lirih. "Catanya gimana, Kang?" (Entrok,2010:33).

Berdasarkan kutipan di atas letak sebuah feminisme liberal dalam bentuk ketidaksetaraan antara lakilaki dan perempuan pada kutipan "Ni, kamu ada-ada saja. Nggak ada perempuan nguli, Nggak akan kuat. Sudah, perempuan itu kerja yang ringan-ringan aja. Ngupas singkong." Hal tersebut memperlihatkan bahwa perempuan hanya berkerja sebagai pengupas singkong yang diupahi dengan bahan makanan. Sedangkang lakilaki mereka diupahi dengan uang.

3. Penindasan

Laki-laki

Terhadap Perempuan
Penindasan laki-laki terhadap perempuan adalah kondisi yang bisa dilihat dari adanya tindakan diskriminasi pada perempuan, yang mengakibatkan laki-laki terlihat berada di atas segalanya. Terkait hal ini, pertanyaan yang muncul ialah apakah penindasan secara seksual, rasial dan kelas secara esensi merupakan hal yang sama serta apakah penindasan perempuan memiliki karakter teoritikal yang spesifik. Dalam novel ini terdapat penindasan lakilaki terhadap perempuan karna perempuan selalu berusaha untuk hidupnya dan keluarganya sendiri sedangkan laki-laki hanya mengandalkan perempuan. Lakilaki mengandalkan perempuan agar hidupnya lebih baik karna mereka tidak berkerja dan mendapatkan segalanya dari wanita. Hal tersebut dapat dilihat pada kutipan di bawah ini:

"Dasar Teja, lanangan ngak tahu diuntung. Susah payah aku cari duit, dia mala enak-enakan kelonan sama kledek". "Ibu sudah tidak memaki tonah. Kini dia mengumpat bapak. Padahal orang yang dimaki entah sedang dimana. Teja yang pemalas. Teja yang tidurnya seperti kerbau. Teja yang hanya mau enaknya sendiri. Teja yang sekarang sedang gandrung dengan kledek." (Entrok,2010:53).

Dalam kutipan diatas, dapat diartikan bahwa wanita selalu berusaha dan bersusah payah untuk hidupnya namun laki-laki senaknya sendiri memperlakukan wanita. Bentuk ketidaksetaraan antara laki-laki dan perempuan bisa dilihat dari perlakuan teja terhadap marni dalam kutipan 
diatas teja sebagai laki-laki malah tidur-tiduran, bermain perempuan sedangkan istrinya berkerja.

Penindasan laki-laki terhdap perempuan juga disebut sebagai laki-laki berkuasa mengandalkan perempuan. Laki-laki menindas perempuan agar merka berkerja keras sedangan laki-laki lebih memilih bermain derngan perempuan lain atau menhabiskan waktunya dengan tidak berkerja. Perempuan berkerja keras demi kelangsungan hidupnya tapi perempuan tersebut dihina. Hal tersebut dapat dilihat pada kutipan di bawah ini:

"Pak waji bukan Yu sri yang memaki-maki ibu dan nyulut pertengkaran. Dia menolak membayar, dengan bahasa yang halus dan santun, khas priyayi. Tapi dalam perkataan yang halus itu terselip paku yang menancap tajam ditelinga siapa pun yang mendengar". "Ya maaf, yu, tiga bulan ini memang belum bayar cicilan. Duitnya lagi buat beli pupuk, sawahku lagi mulai tanam. Kalau sampeyan nagih sekarang ya tidak bisa. Mau di geledah juga tidak ada duitnya". "Ya saya bukannya nggak percaya, pak guru. Tapi saya memang lagi kepepet. Duitnya mau di pakai nyumbang kampanye, besok pak lurah mau dating buat ngambil duit". "Ya sudahlah, yu. Duitmu di orang lain kan masih banyak. Tagih saja mereka. Daripada anakmu malu nanti, semua temanya tau ibunya rentenir. Lintah Darat. Orang yang jelas-jelas di kutuk agama". "Pak guru, sampeyan jangan bicara seperti itu". "Ya nyatanya seperti itu. Makanya ya sudah, nagih ke yang lain aja!" (Entrok,2010:84).

Dalam kutipan di atas, dapat diartikan bahwa laki-laki merendahkan seorang perempuan yang sedang berjuang demi makan keluarganya. Bentuk penindasan laki-laki terhadap perempuan dapat dilihat dari kutipan diatas seorang laki-laki sedang memaki atau menindas seorang perempuan dengan kata-kata kasarnya.

\section{PEMBAHASAN}

Berdasarkan hasil penelitian tentang feminisme liberal dalam novel Entok karya Okky Madasari yang terkait bentuk ketidakadilan gender, ketidaksetaraan antara lakilaki dan perempuan, serta penindasan laki-laki terhadap perempuan tak dapat dipisahkan dari segi kehidupan dalam novel Entrok karya Okky Madasari.

Ketidakadilan gender merupakan kondisi kesenjangan akibat dari sistem tersebut. Ketidakadilan dan diskrimiasi gender terjadi keyakinan yang ditanamkan masyarakat dalam berbagai bentuk. Perempuan selalu terlihat lebih rendah dari pada lakilaki, perempuan lah yang lebih banyak merasakan ketidakadilan gender.

Pada penelitian terdahulu mengenai feminisme yang di lakukan oleh Rani Nuraeni yang berjudul Feminisme Dalam Novel Perempuan Berkalung Sorban Karya Abidah El Khaliqy. Penelitin terdahulu yang di tulis oleh Rani Nuraeni lebih membahas tentang femisme gender, marginalisasi, subordinasi, kekerasan, beban kerja. Sedangkan penelitian ini mengunakan feminisme liberal teori bentuk penindasan gender yang mengambarkan tentang sosok perempuan yang berkerja keras untuk 
kelangsungan hidupnya dan keluarganya sendiri dengan berjualan. Novel ini juga mengambarkan ketidakadilan dan deskriminasi gender yang terjadi kerena adanya keyakinan pada masyarakat. Perempuan selalu terlihat lebih rendah dari pada laki-laki, perempuan lah yang lebih banyak myerasakan ketidakadilan gender.

Ketidaksetaraan antara laki-laki dan perempuan merupakan kondisi laki-laki dengan perempuan untuk memperoleh kesempatan dan hakhaknya. Ketidaksetaraan dalam ekonomi, hukum, sosial budaya, pendidikan, dan keamanan, serta kesamaan dalam menikmati hasil pembagunan tersebut.

Pada penelitian terdahulu mengeni feminisme yang diteliti oleh Indayani yang berjudul Feminisme dalam Novel Bibir Merah Karya Achmad Munif terdiri atas beberapa pembahasan dari rumusan masalah yang diteliti. Peneliti ini membahas tentang Trauma yang dialami Rumanti. Sedangkan penelitiaan ini menggunakan feminisme liberal teori ketidaksetaraan antara laki-laki dan perempuan. Ketidaksamaan antara laki-laki dengan perempuan untuk memperoleh kesempatan dan hakhaknya. Ketidaksetaraan dalam ekonomi, hukum, sosial budaya, pendidikan, dan keamanan, serta kesamaan dalam menikmati hasil pembagunan tersebut.

Penindasan laki-laki terhadap perempuan karna perempuan selalu berusaha untuk hidupnya dan keluarganya sendiri sedangkan lakilaki hanya mengandalkan perempuan. Laki-laki mengandalkan perempuan agar hidupnya lebih baik karna mereka tidak berkerja dan mendapatkan segalanya dari wanita. Perempuan juga mengalami penindasan berupa kat-kata atau ucapan yang tidak baik oleh masyarakat. Pada dasarnya perempuan berkerja keras demi kelurganya agar hidup berkecukupan namun perempuan selalu dapat cacian dan ucapan tidak baik dari masyarakat.

\section{SIMPULAN DAN SARAN}

Berdasarkan hasil penelitian dan pembahasan dalam penelitian Feminisme Liberal dalam Novel Entrok Karya Okky Madasari ini dapat disimpulkan bahwa bentuk ketidakadilan gender ditunjukkan adanya penindasan atau penghinaan masyarakat untuk perempuan mereka berfikir semua yang dilakukan perempuan tidak baik. Sedangkan ketidaksetaraan antara laki-laki dan perempuan ditunjukkan adanya perbedaan dalam hal perkerjaan, hakhak sebagai manusia, pendidikan, pertahanan dan keamanan nasional, serta kesamaan dalam menikmati hasil pembangunan tersebut, penindasan laki-laki terhadap perempuan ditunjukkan pada kondisi yang bisa dilihat dari adanya tindakan diskriminasi pada perempuan, yang mengakibatkan laki-laki terlihat berada di atas segalanya.

Berdasarkan hasil penelitian dapat dikemukakan saran sebagai berikut.

Hasil penelitian ini bermanfaat untuk menambah wawasan bagi pembaca khususnya tentang feminisme liberal. Penelitian ini dapat ditindaklanjuti oleh peneliti lain dengan sudut pandang yang berbeda.

\section{DAFTAR PUSTAKA}

Arikunto, Suharismi. 2002. Prosedur Penelitian, Suatu Pendekatan Praktek. Rineka Cipta. Jakarta. 
Madasari,Okky. 2010. Entrok. Cetakan pertama, cetakan ke dua tahun 2015. Jakarta: PT Gramedia Pustaka Utara

Nurgiyantoro, Burhan. 2013. Teori Pengkajian Fiksi. Yogyakarta: Gadjah Mada University Press.
Sugihastuti dan Suharto, 2002. Kritik Sastra Feminis: Teori dan Aplikasinya. Yogyakarta: Pustaka Pelajar.

Teeuw, A. 2003. Sastra dan Ilmu Sastra. Penerbit: Dunia Pustaka Jaya, Jakarta. 